\title{
Correção cirúrgica de entrópio em cães da raça Rottweiler
}

\section{Surgical correction of entropion in Rottweiler breed dogs}

\author{
Duvaldo Eurides ${ }^{1}$, Maria Clorinda Soares Fioravanti' ${ }^{2}$, Luiz Antônio Franco da Silva², \\ Nilo Sérgio Troncoso Chaves ${ }^{2}$, Neide Maria da Silva ${ }^{3}$
}

\begin{abstract}
Resumo
Vinte e seis cães da raça Rottweiler, com idade entre 4 e 9 meses, portadores de entrópio lateral, foram submetidos à remoção de um segmento de pele em forma de "V", ao redor da comissura palpebral lateral, envolvendo as pálpebras superior e inferior. Aproximou-se o músculo orbicular do olho com pontos de Lembert e a pele com pontos simples interrompidos. Os procedimentos ocasionaram restauração da tensão da comissura e correção da inversão palpebral. O método empregado mostrou-se eficiente podendo ser indicado para corrigir entropia lateral de cães jovens da raça Rottweiler.
\end{abstract}

Palavras chave: cão; pálpebra; entrópio; cirurgia

\section{Introdução}

O entrópio em cães pode ser anatômico, espástico e cicatricial. O tipo anatômico é o mais comum e se deve a defeitos na comissura palpebral lateral. Na maioria dos casos resulta de anormalidades anatômicas da conformação globo ocular-pálpebra (Barrie 1986). O comprimento, a rigidez e a musculatura das pálpebras em relação ao globo ocular são fatores determinantes no entrópio anatômico de cães das raças Rottweiler. Em geral o entrópio é uma alteração hereditária que pode ser herdada por um gene autossômico dominante de penetrança completa (Peiffer et al. 1987) ou ser devido à traumatismo ou blefarospasmo (Severin 1991).

Em cães de grande porte foi observada inversão lateral ou medial com entropia central das pálpebras superior e inferior. A etiopatogenia envolveu uma debilidade congênita das estruturas da comissura palpebral lateral. A irritação ocular desencadeou um aumento no reflexo e no espasmo do músculo orbicular do olho. $O$ tônus aumentado acentuou a inversão da margem palpebral, a triquíase e a irritação, contribuindo para o o blefarospasmo (Peiffer et al. 1987).

Barrie (1986), Cook e Peiffer (1986) e Peiffer et al. (1987) citaram, para o reparo de entropia de cães, a remoção de um segmento elíptico de pele e músculo orbicular do olho cerca de 1 a $4 \mathrm{~mm}$ da margem palpebral.
As bordas da pele foram aproximadas em pontos simples com fio inabsorvível. Em cães da raça Rottweiler, com entropia lateral, Gross (1996) recomendou aumentar a tensão no canto lateral das pálpebras através de incisão de pele em forma de "Y" cerca de 1 a $2 \mathrm{~mm}$ da margem palpebral, remover as bordas de pele da incisão expondo o músculo orbicular do olho e ancorando-o no periósteo do processo temporal do osso zigomático com fio absorvível. Gellatt (1991), no entanto, indicou a remoção de um segmento de pele em forma de "V" na comissura palpebral lateral envolvendo as pálpebras superior e inferior. Para cães portadores de pálpebra inferior longa, sobressaltante e de pouca rigidez, Gross (1996) recomendou a retirada de um segmento triangular de pele da comissura palpebral lateral para encurtar e erguer a pálpebra.

No entrópio da pálpebra inferior que comprometia quase toda sua extensão, Severin (1991) e Gross (1996) recomendaram remover com tesoura uma tira elíptica de pele e do músculo orbicular do olho ventralmente ao entrópio cerca de 2 a $4 \mathrm{~mm}$ da borda palpebral. Slatter (1992), no entanto, não incluiu ao método a remoção de um segmento do músculo orbicular do olho. Os autores realizaram aproximação de pele com pontos simples separados de fio de seda ou náilon. No pós-operatório Gross (1996) sugeriu colocar no pescoço do cão um colar tipo elisabetano. Slatter (1992) e Gross (1996) citaram como complicações da correção do entrópio a supereversão ou subcorreção das pálpebras.

Para correção do entrópio congênito bilateral de cão da raça Springer Spaniel, Kuhns (1982) fixou as pálpebras na comissura palpebral lateral com pinça triangular de calázio, removeu com bisturi um segmento de pele, a $2 \mathrm{~mm}$ da borda, que foi aproximada com fio de seda. Para corrigir entrópio de cães, de 2 a 5 meses de idade, Tinsley (1987) recomendou aplicar um ponto de Wolff captonado a $3 \mathrm{~mm}$ das margens palpebrais superior $\mathrm{e}$ inferior.

Cook e Peiffer (1986) corrigiram entrópio de cães com idade de 6 meses, quando os traços faciais, principalmente as pálpebras, apresentavam conformações de cães adultos.

\footnotetext{
Departamento de Medicina Animal, Universidade Federal de Uberlândia, UFU, Av. Pará 1720, Campus Umuarama, $38400-902$ Uberlândia, MG, Brasil

2 Departamento de Clínica, Escola de Veterinária, Universidade Federal de Goiás, UFG, Goiânia, GO, Brasil

${ }^{3}$ Departamento de Parasitologia e Imunologia, UFU
} 
Considerando que a bibliografia disponível sobre o entrópio de cães da raça Rottweiler é escassa, e dada a importância do assunto, objetivou-se neste trabalho relatar casos de entrópio na comissura palpebral lateral e apresentar uma técnica cirúrgica de correção.

\section{Material e Métodos}

- Vinte e seis cães da raça Rottweiler, com idade variando de 5 a 9 meses, apresentavam ao exame clínico blefarospasmo espástico, epífora, conjuntivite e entrópio bilateral nas comissuras palpebrais laterais, envolvendo as pálpebras superiores e, severamente, as inferiores. Aparentemente as pálpebras eram grandes em relação ao globo ocular e as comissuras palpebrais laterais arredondadas. Em 18 animais observou-se que o entrópio abrangia dois terço das pálpebras superiores; em 8 o envolvimento era menor. Devido ao constante roçar dos pêlos palpebrais, 9 animais apresentavam ulcerações superficiais ou profundas de suas córneas e conjuntivites. As pálpebras não apresentavam triquíase e sinais de traumatismo. A severidade do espasmo das pálpebras inferiores variava, mesmo nos casos de conjuntivite e ulceração de córnea. A variação da intensidade dos sintomas era proporcional ao grau e tempo de inversão das pálpebras.

A determinação da extensão da inversão e correção anatômica requerida foi estimada pela pressão digital aplicada junto às bases das pálpebras para inverter suas margens à posição normal. Dado o diagnóstico de entropia lateral e conjuntivite, os animais, portadores ou não de ulceração de córnea, foram submetidos ao tratamento préoperatório com cloranfenicol ${ }^{1}$, via intramuscular $(25 \mathrm{mg} /$ $\mathrm{kg}$ de $12 \mathrm{em} 12 \mathrm{~h}$ ), em forma de colírio², (duas gotas de 4 em $4 \mathrm{~h}$ ), pomada oftálmica ${ }^{3}$ à noite e predinisolona ${ }^{4}(1$ $\mathrm{mg} / \mathrm{kg}$ de peso corporal), via oral, $24 \mathrm{~h}$ antes da cirurgia.

Os cães foram sedados com maleato de acepromazina ${ }^{5}$ a $0,2 \%$ via endovenosa $(0,2 \mathrm{mg} / \mathrm{kg}$ de peso corporal). A indução anestésica foi feita pela administração, em máscara, da associação oxigênio, óxido nitroso e halotano. Após, foram submetidos a intubação oro-traqueal e conectados a um sistema fechado de anestesia recebendo a mesma associação anestésica.

Adotadas as medidas de tricotomia e anti-sepsia, foi removido um segmento de pele em forma de "V" com o vértice voltado para a comissura palpebral lateral, envolvendo as pálpebras superior e inferior, cerca de $4 \mathrm{~mm}$ da

\footnotetext{
1 Quemicetina, Laboratório Carlo Herba, Duque de Caxias, RJ

2 Cloranfenicol colírio, Laboratório Frumtost, Guarulhos, SP

${ }^{3}$ Cloranfenicol pomada oftálmica, Laboratório Frumtost, Guarulhos, SP

${ }^{4}$ Meticorten, Schering-Plough, Rio de Janeiro, RJ

${ }^{5}$ Acepran $1 \%$, Univet . Industria Veterinária, São Paulo, SP

${ }^{6}$ Vicryl, Ethicon, Laboratório Johnson \& Johnson, São José dos Cam pos, SP
}

margem palpebral para exposição do músculo orbicular do olho. O comprimento e a largura da pele removida variavam com a intensidade da inversão palpebral; no entanto, em todos os animais o segmento de pele removido da pálpebra inferior foi comprido (Fig. 1). Para eversão das pálpebras foram aplicados pontos de sutura tipo Lembert no músculo orbicular do olho, próximo às bordas laterais da incisão de pele (Fig. 2) e nesta foram usados pontos simples separados (Fig. 3). Os pontos de sutura foram iniciados no vértice do "V" com fio polyglactina $910^{6}$, 5-0.

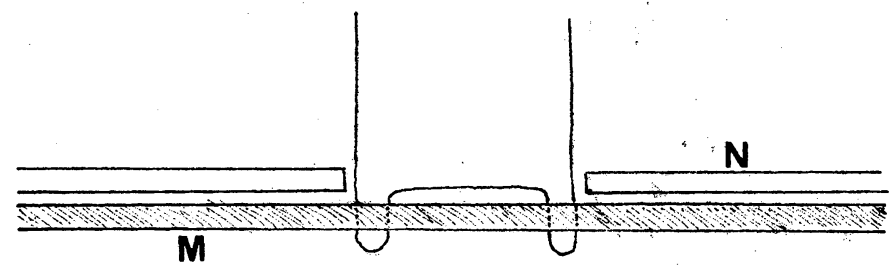

Figura 1 - Representação esquemática do globo ocular e pálpebras. Aspecto da incisão em forma de " $V$ " e representação do local da aplicação do primeiro ponto tipo Lembert, envolvendo o músculo orbicular do olho, para correção de entrópio das pálpebras superior e inferior de cães da raça Rottweiler.

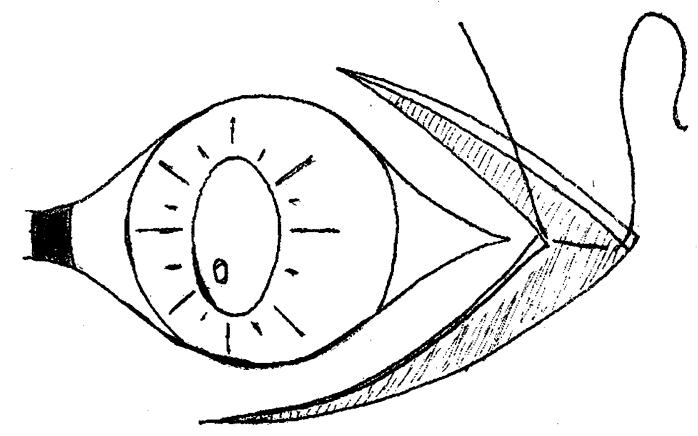

Figura 2 - Representação esquemática da aplicação de um ponto de Lembert, para aproximação do músculo orbicular do olho $(\mathrm{M})$, próximo à borda da ferida de pele $(\mathrm{N})$, para correção de entrópio das pálpebras superior e inferior de cães da raça Rottweiler.

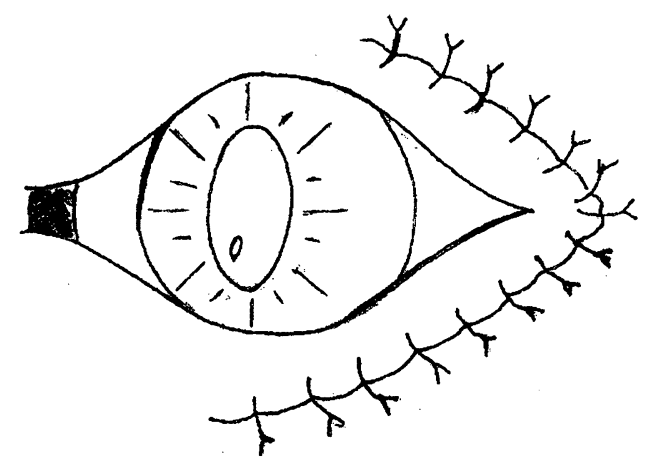

Figura 3 - Representação esquemática do globo ocular e pálpebras, notificando a aproximação da pele das pálpebras superior e inferior com pontos simples separados, para correção de entrópio das pálpebras superior e inferior de cães da raça Rottweiler. 
No pós-operatório os animais continuaram recebendo a medicação prescrita no pré-operatório, durante 8 dias; a predinisolona foi administrada diariamente por 3 dias. Para evitar que os animais se traumatizassem, eles foram submetidos a um colar tipo elisabetano durante 10 dias, quando os pontos de pele foram removidos. Os animais foram observados por um período de 120 dias para avaliar a efetividade da correção cirúrgica do entrópio.

\section{Resultados}

Nos 3 primeiros dias de pós-operatório observou-se, em 7 animais $(26,9 \%)$ operados, presença de edema nas pálpebras superior e inferior com supereversão.

Os cães com entropia lateral submetidos ao método cirúrgico proposto recuperaram-se da inversão decorridos de 7 a 10 dias da cirurgia.

Os pontos de fio polyglactina 910 para aproximação do músculo orbicular do olho e pele não ocasionaram complicações locais, foram de fácil aplicação e eficientes para corrigir o entrópio na comissura palpebral lateral.

A utilização do colar tipo elisabetano foi eficiente para evitar que os animais se traumatizassem no período pósoperatório.

No período final de observação, 120 dias após a cirurgia, os animais apresentavam as pálpebras normais ao exame clínico.

\section{Discussão}

A etiopatogenia do entrópio observado nesta pesquisa provavelmente envolveu uma debilidade do músculo orbicular do olho, o que ocasionou anormalidade anatômica da conformação globo ocular-pálpebra, como encontrou Barrie (1986). Os animais apresentavam a comissura palpebral lateral arredondada que possivelmente levou à falta de tensão da comissura palpebral lateral (Peiffer et al. 1987) e pálpebra inferior sobressaltante (Gross 1996).

Nos cães portadores de úlceras de córnea e conjuntivites crônicas, a intensidade do entrópio era aparentemente maior, provavelmente devido a contrações espásticas dos músculos orbiculares do olho.

Para correção do entrópio lateral Barrie (1986), Cook e Peiffer (1986) e Peiffer et al. (1987), recomendaram remover um segmento elíptico de pele e do músculo orbicular do olho. Em cães da raça Rottweiler, Gross (1996), no entanto, citou a necessidade de aumentar a tensão da comissura palpebral lateral das pálpebras através do ancoramento do músculo orbicular do olho no periósteo do processo temporal do osso zigomático. Devido aos resultados obtidos neste experimento, a tensão provocada no músculo orbicular do olho, em toda a extensão da ferida de pele, pelos pontos tipo Lembert e aproximação da pele, contribuiram para correção da tensão lateral da comissura palpebral lateral e da eversão palpebral, substituindo, portanto, a remoção de uma porção do músculo orbicular recomendada por Barrie (1986), Cook e Peiffer (1986), Peiffer et al. (1987) e Gross (1996).

O comprimento do segmento de pele removido foi relacionado ao seu envolvimento na inversão como referido por Peiffer et al. (1987) e determinado por pressão digital aplicada junto às bases das pálpebras. A remoção, somada à tensão provocada no músculo orbicular do olho e na pele pelos de pontos de sutura, promoveu a correção da inversão das pálpebras superior e inferior.

O método descrito neste experimento foi aplicado em cães em crescimento, com idades de 5 a 9 meses, não sendo porém observada supereversão ou subcorreção, como referido por Slatter (1992) e Gross (1996), provavelmente porque os animais já apresentavam traços faciais definidos (Cook e Peiffer 1986). A recomendação feita por Tinsley (1987), de aplicar na comissura palpebral lateral pontos de Wolff captonado através das pálpebras superior e inferior, para everter pálpebras de cães jovens, pode não ser eficiente quando a alteração estiver relacionada à deficiência do músculo orbicular do olho. O método proposto foi eficiente e de fácil aplicação, não sendo necessários instrumentos especiais para auxiliar na demarcação do local da remoção dos segmentos de pele, como sugerido por Kuhns (1982).

A utilização do fio polyglactina 910 para síntese do músculo orbicular do olho e pele demonstrou ser eficiente por não ocasionar reações locais indesejáveis, permanecer integro às estruturas envolvidas e permitir uma cicatrização uniforme. Não se pode afirmar, no entanto, uma padronização do tipo de pontos e fios empregados para reparo do entrópio já que Severin (1991) e Slatter (1992), utilizaram pontos simples separados na pele com fio de seda ou náilon e Gross (1996) empregou fio absorvível para ancorar o músculo orbicular do olho no periósteo.

As complicações verificadas nas correções do entrópio como supereversão e subeversão, citadas por Slatter (1992) e Gross (1996), podem ser observadas devido a falta de habilidade do cirurgião, processo inflamatório ou infeccioso local ou quando os animais interferem na ferida. A utilização do colar tipo elisabetano, utilizado neste experimento, como referido por Gross (1996), evitou que os animais se autotraumatizassem, interferindo na reparação cicatricial.

O segmento cutâneo removido da pálpebra inferior foi mais longo devido à maior intensidade da eversão e foi suficiente para corrigir o entrópio. A incisão de pele de cerca de $4 \mathrm{~mm}$ da borda palpebral, a exemplo do método citato por Barrie (1986), Cook e Peiffer (1986) e Peiffer et al. (1987), associada à aproximação do músculo orbicular do olho e pele, não ocasionou, durante o período de obsevação, alterações aparentes da borda palpebral. 


\section{Conclusão}

Baseados nos resultados obtidos pode-se concluir que a tensão provocada no músculo orbicular do olho através da aplicação de pontos de Lembert, somada à remoção elíptica de pele na comissura palpebral lateral em forma de "V", envolvendo as pálpebras superior e inferior e a aproximação de pele, foram capazes de corrigir o entrópio anatômico de cães jovens da raça Rottweiler.

\section{Abstract}

\section{Surgical correction of entropion in Rottweiler breed dogs}

Twenty six Rottweiler breed dogs with lateral canthus entropion had an eliptical skin segment removed by surgery around the lateral palpebral commissure of the orbicular muscle and skin. The orbicualr muscle was aproximated with Lembert and separated stitches. This procedure could restore the lateral canthus tension and correct the palpebral inversion. The method was efficient to correct lateral canthus entropion in young Rottweiller breed dogs.

Key words: dog; eye-lid; entropion; surgery

\section{Referências bibliográficas}

Barrie KP 1986. Olhos, cap. 6, p. 34-47. In MJ Bojrab, Cirurgia dos Pequenos Animai, 2a. ed., Roca, São Paulo.

Cook CS, Peiffer RL 1986. Complicações da cirurgia ocular. Cães \& Gatos 8: 13-22.

Gelatt KN 1991. The canine eyelids, cap. 6, p. 256-275. In KN Gelatt, Veterinary Ophthalmology, 2nd ed., Lea \& Febiger, Philadelphia.

Nomina Anatomica Veterinária 1983. 3a. ed., Internacional Committee on Veterinary Gross Anatomical Nomenclature, New York, $209 \mathrm{pp}$.

Gross SL 1996. Pálpebras, cap. 8, p. 66-126. In MJ Bojrab, Técnicas Atuais em Cirurgia de Pequenos Animais, Roca, São Paulo.

Kuhns EL 1982. Repair of congenital bilateral entropion in dog. Vet Med Small An Clin 8: 1198-1201.

Peiffer RL, Nasise MP, Cook CS, Harling DE 1987. Surgery of the canine and feline orbit, adnexa and blobe part 3: other strutural abnomallities and enoplasia of the eyelid. Companion animal practice - Ophthalmology 18: 20-35.

Severin GL 1991. Manual de Oftalmologia Veterinaria, Hemiferio Sur, Buenos Aires, 203 pp.

Slatter DH 1992. Fundamental of Veterinary Ophthamology, W.B. Saunders, Philadelphia, $821 \mathrm{pp}$.

Tinsley PE 1987. A simples procedure for the correction of bilateral entropion in puppies. Modern Vet Practice 68 (6): 347350. 